\title{
A IMUNIDADE TRIBUTÁRIA APLICADA AOS LIVROS ELETRÔNICOS E E- READERS
}

\section{TAX IMMUNITY APPLIED TO ELETRONIC BOOKS AND E-READERS}

\author{
1'Thiago Lima Carneiro \\ ${ }^{2}$ Karina da Silva Meneses
}

\section{RESUMO}

A Constituição Federal de 1988 determina a imunidade tributária dos livros e do papel destinado à sua produção, a fim de difundir o conhecimento e garantir a liberdade de expressão. Ocorre que o desenvolvimento tecnológico acarretou o surgimento de livros eletrônicos e aparelhos destinados à sua leitura, os chamados e-readers. Diante desse novo paradigma, resta necessário reavaliar o texto constitucional a fim de mantê-lo atualizado. A jurisprudência brasileira não é uníssona quanto ao assunto e está a cargo do STF julgar tal questão. A partir de uma interpretação axiológica da norma, deve-se chegar à melhor compreensão deste instituto imunizante.

Palavras-chave: Imunidade tributária, Livros eletrônicos, Desenvolvimento tecnológico, Liberdade de expressão

\begin{abstract}
The Federal Constitution of 1988 determines the tax immunity of books and paper used for their production in order to contribute to the dissemination of knowledge and guarantee freedom of expression. On the other hand, technological development has enabled the creation of electronic books and devices for reading, called e-readers. In this new paradigm, it remains necessary to reassess the Constitution in order to keep it updated. Is the responsibility of the Supreme Court judge this case without the need for law production. From an axiological interpretation of the rule, it must come to a better understanding of this institute.
\end{abstract}

Keywords: Tax immunity, Ebooks, Technological development, Freedom of expression

\footnotetext{
${ }^{1}$ Mestrando em Direitos Humanos pela Universidade Federal do Pará - UFPA, Belém, Pará, (Brasil). E-mail: t.thiagolima@gmail.com

${ }^{2}$ Mestranda em Direitos Humanos pela Universidade Federal do Pará - UFPA, Belém, Pará. (Brasil). E-mail: ksm_karina@hotmail.com
} 


\section{1- INTRODUÇÃO}

As imunidades constantes na Constituição Federal de 1988 são normas negativas de delimitação de competência tributária, ou seja, o constituinte objetivou não tributar certos objetos e pessoas visando com isso garantir princípios constitucionais fundamentais.

A partir daí, nota-se que a imunidade presente no artigo 150, VI, "d" do texto constitucional possui a função de garantir a liberdade de comunicação, propiciar maior acesso à cultura, à educação e à informação, através do barateamento dos livros.

Ocorre que a interpretação desse dispositivo tem sido controvertida quanto à sua extensão, tendo em vista a atual adoção de livros eletrônicos em âmbito social por conta da evolução tecnológica, que acarreta mudança na forma de consumir esses meios de informação e cultura pelos indivíduos, em contrapartida à ausência de previsão normativa expressa acerca da imunidade tributária dos mesmos.

É sabido que a educação é mecanismo de preservação da dignidade da pessoa humana e base para a democracia, pois quanto mais educado for um povo, mais facilmente exercitará os postulados democráticos da igualdade e da liberdade. Sendo assim, pode-se dizer que é por meio da educação que os fundamentos do Estado Democrático de Direito podem ser realizados e os objetivos da República Federativa do Brasil atingidos.

Sendo assim, a partir de uma interpretação axiológica, imprescindível analisar se os livros eletrônicos - bem como os aparelhos criados especificamente para sua leitura - devem ser abarcados pela imunidade tributária prevista no texto constitucional ou se a desoneração deve se restringir ao livro desenvolvido em papel, seguindo fielmente os termos dispostos pela Carta Magna, relegando à mesma perspectiva progressista.

Para tanto, faz-se necessário compreender o histórico e o conceito do instituto imunizante previsto no art. 150, VI, alínea d da Constituição Federal, para construir as bases para que se possa aplicar a interpretação axiológica proposta por este trabalho, ressaltando o contex to do surgimento do referido dispositivo, bem como avaliar como é visto atualmente pela doutrina.

Uma vez definidas as bases para a interpretação da finalidade da norma, analisar-se-á a possibilidade de extensão da desoneração em questão aos livros eletrônicos (e-books) e aos leitores digitais (e-reardes), aparelhos desenvolvidos especificamente para a leitura dos livros eletrônicos. Para tanto, avaliaremos a aplicabilidade da norma a partir de uma interpretação 
axiológica, bem como relacionaremos o instituo imunizante aos princípios constitucionais fundamentais, como o da dignidade da pessoa humana. Por ser imprescindível neste trabalho, analisaremos também distinção entre os e-readers e os aparelhos que apenas incorporam sua função, como tablets e outros dispositivos móveis.

Por fim, conclui-se pela análise do instituto imunizante a partir dos principais julgados do Supremo Tribunal Federal acerca do dispositivo em questão, demonstrando qual norte a Suprema Corte tem tomado quando do julgamento de casos semelhantes, apontando qual seria a melhor forma de interpretar a desoneração prevista no art. 150, VI, d da Constituição Federal.

\section{2- A IMUNIDADE TRIBUTÁRIA DO LIVRO}

Segundo Hugo de Brito Machado, “a imunidade é o obstáculo decorrente da regra da Constituição à incidência de regra jurídica de tributação. O que é imune não pode ser tributado. A imunidade impede que a lei defina como hipótese de incidência tributária aquilo que é imune". (MACHADO, 2014, p. 288). Nesse diapasão, preleciona Regina Helena Costa: “os princípios são diretrizes positivas, norteadoras do adequado exercício da competência tributária, as imunidades encerram preceitos negativos, demarcando a própria competência tributária, impedindo seu exercício em relação a determinadas pessoas, bens e situações. " (COSTA, 2001, p. 35).

O berço da imunidade tributária sobre os livros surgiu no Brasil em 1946, como reação às medidas restritivas às importações de papel e à livre manifestação de pensamento adotadas no Estado Novo. Segundo Carraza, a imunidade em tela é tipicamente objetiva, ou seja, não importa a pessoa a quem pertença o livro, o jornal ou periódico, ou o papel, sendo este último imune por conta da sua destinação. (CARRAZA, 2014, p. 294).

Segundo Torres, a vedação abrangia "papel destinado exclusivamente à impressão de jornais, periódicos e livros” (art. 31, VI, c). A Constituição de 1946 dizia ainda, no art. 203, que "nenhum imposto gravará diretamente os direitos do autor, nem a remuneração de professores e jornalistas" (TORRES, 2005, p. 296).

A partir da Constituição de 1967, passando pela Emenda de 1969 e chegando ao texto de 1988, afirmou-se a proibição de instituir impostos sobre os livros, jornais, periódicos e o papel destinado a sua impressão. 
Assim dispõe o texto da Carta Magna de 1988:

Art. 150. Sem prejuízo de outras garantias asseguradas ao contribuinte, é vedado à União, aos Estados, ao Distrito Federal e aos Municípios:

VI - Instituir impostos sobre:

d) livros, jornais, periódicos e o papel destinado a sua impressão.

Nota-se que o referido dispositivo, ao vedar a instituição de tributos sobre os livros, almeja facilitar a busca do conhecimento, elemento indispensável para concretização da dignidade da pessoa humana, já que reduz os custos de produção do produto.

Nesse sentido ensina Carrazza:

Com toda a facilidade notamos que o que a Constituição pretende, neste ponto, é garantir a liberdade de comunicação e de pensamento (aí compreendida a liberdade de imprensa) e, ao mesmo tempo, facilitar a difusão da cultura e a própria educação do povo. Em outras palavras, quer facilitar a busca do conhecimento, bem inefável que agrega dignidade à pessoa humana. (CARRAZZA, 2013, p. 904).

Além do mais, segundo o referido autor, ninguém contesta que a Nação Brasileira só se desenvolverá quando todos tiverem real acesso à educação, à informação e à cultura. Tal entendimento é pertinente, pois, hoje em 2015, o Brasil ainda é um país deficiente no campo da educação, especialmente em relação ao ensino básico. Sem dúvidas, o constituinte, quando da elaboração do texto constitucional, observou essa difícil situação nacional ao criar a imunidade em tela.

A liberdade de pensamento acaba contribuindo decisivamente para a difusão da cultura. Para Carrazza (2013), trata-se de uma decorrência lógica, já que, quando maior for a produção intelectual no país, maior será a gama de conhecimento disponível à população. Facilitar o acesso a esse material igualmente contribuirá para o desenvolvimento da Nação.

Ainda nesse sentido, segundo Carrazza, o País não pode prescindir de veículos de comunicação, como os livros, jornais e periódicos. Para ele, "é por intermédio de todos eles que as pessoas têm acesso às informações, às artes, à cultura, ao lazer, às práticas religiosas, às ações governamentais etc.” (CARRAZZA, 2013, p. 906).

Dessa forma, a imunidade em questão, em verdade, busca concretizar os direitos fundamentais relacionados à livre manifestação de pensamento, de expressão da atividade intelectual, artística, científica e de comunicação, bem como assegurar o acesso à informação e banir qualquer tipo de censura.

Assim aduz Carrazza: 
Assim, quando a Constituição Federal prescreve serem imunes aos impostos o livro, o jornal, o periódico e o papel destinado à sua impressão (art. 150, VI, "d"), ela não está senão dando efetividade aos direitos fundamentais à livre "manifestação de pensamento" (art. 5 , IV) e de "expressão de atividade intelectual, artística, científica e de comunicação" (art. 5०, IX). Também tem em mira (i) assegurar a todos o "acesso a informação" (art. $5^{\circ}$, XIV), (ii) evitar venha de algum modo embaraçada a "plena liberdade de informação jornalística em qualquer veículo de comunicação social" (art. 220, $\S 1^{\circ}$ ) e (iii) banir qualquer censura "de natureza política, ideológica e artística" (art. 220, $\S 2^{\circ}$ ). (CARRAZZA, 2013, p. 906).

Portanto, o constituinte criou meios materiais para efetivar os direitos fundamentais supramencionados, buscando o interesse da sociedade, já que esse instituto afasta procedimentos capazes de inibir a produção material e intelectual de livros, jornais e periódicos. Nesse mesmo sentido, ensina Kiyoshi Harada: “A Carta Magna, ao imunizar os livros, jornais, periódicos e o papel destinado à sua impressão, teve por objetivo incentivar a cultura em geral e garantir a livre manifestação de pensamento e do direito de crítica". (HARADA, 2016, p. 424).

Por outro lado, segundo Torres, a proteção do art. 150, VI, “d” não é verdadeira imunidade tributária, mas sim instrumento de justiça ou de utilidade. De forma crítica, o referido autor insere a imunidade sobre livros como "privilégio constitucional".

Nesse sentido:

A proteção do art. 150, VI, $d$ não é vera imunidade tributária. Falta-lhe o traço característico: ser atributo dos direitos fundamentais e constituir garantia da liberdade de expressão. O seu fundamento, como adiante veremos, está na idéia de justiça ou de utilidade. Categoriza-se melhor, portanto, como privilégio constitucional, podendo em alguns casos, como no dos jornais, assumir o aspecto de privilégio odioso. (TORRES, 2005, p. 297).

Ainda segundo o supracitado autor, não se vislumbra no direito comparado exemplo de imunidade tributária para jornais e livros. Assevera também que "esse instituto não deve ter a característica da irrevogabilidade, como acontece nas verdadeiras imunidades". (TORRES, 2005, p. 297).

De qualquer forma, Torres corrobora seu entendimento junto ao de Carrazza ao reconhecer que o fundamento da intributabilidade dos livros, jornais e periódicos encontra-se ideia de justiça fiscal ou utilidade social, com fito de baratear os custos dos livros e das publicações.

Vejamos o que dispõe Torres nesse sentido: 
O fundamento precípuo da intributabilidade dos livros, jornais e periódicos é a ideia de justiça fiscal, nela incluída a de utilidade social, consubstanciada na necessidade de baratear o custo dos livros e das publicações. Em país com gravíssima crise de educação e com a necessidade premente de se ampliar o número de pessoas alfabetizadas e instruídas torna-se vital diminuir o custo da produção dos seus instrumentos os mais importantes - os livros e os periódicos. (TORRES, 2005, p. 297).

Torres ressalta que "esse argumento não pode prevalecer para os jornais, que, em uma estrutura liberal de poder, devem ser mantidos pelos seus leitores e anunciantes, sem apoio estatal permanente (...)" (TORRES, 2005, p. 297).

Outrossim, mais especificamente sobre a liberdade de expressão, Torres aduz que a proteção desse direito pode ser utilizada como argumento subalterno, já que a imunidade em tela facilitaria a manifestação de pensamento:

A proteção da liberdade de expressão pode ser utilizada como argumento subalterno, eis que ao se baratear o custo das publicações se estará facilitando a manifestação de pensamento, tendo em vista que a justiça e a liberdade integram a mesma equação valorativa. Mas a intributabilidade do art. 150, VI, $\mathrm{d}$ não encontra nos direitos fundamentais relacionados com a liberdade de expressão o seu fundamento maior. Em 1946, quando surgiu, poderia ter alguma conotação com a liberdade de imprensa, diante das medidas arbitrárias do Estado Novo contra os jornais e os livros e a natural reação que se seguiu. Mas depois, nos períodos de vigência democrática, nenhum risco poderia haver com a cobrança de impostos sobre aqueles instrumentos de expressão política ou cultural, desse que não discriminatória. (TORRES, 2005, p. 298).

Inegável que o fundamento da liberdade de expressão possui mais relação com a imunidade sobre os jornais, instrumentos ligados à imprensa, principalmente por conta da repressão às medidas arbitrárias do Estado Novo. Entretanto, apesar da importância do levantamento histórico acerca do instituo, deve-se projetar o texto constitucional para o futuro, tendo em vista que o mesmo não permanece estático, mas evolui com o passar do tempo.

Nesse diapasão, segundo Carrazza, "a lei - mesmo a lei constitucional -, uma vez editada, adquire um tipo de vida própria. Seu significado não permanece estático, mas evolui com o passar do tempo, seguindo uma linha de desenvolvimento que vai atualizando suas virtualidades" (CARRAZZA, 2013, p. 922).

Sendo assim, mesmo respeitando o posicionamento de Torres, deve-se contemplar outra perspectiva acerca dos fundamentos da imunidade sobre os livros, observando sua legitimidade junto à dignidade da pessoa humana, da livre manifestação de pensamento, sendo indispensável para a difusão de conhecimento e cultura no país. 


\section{3- APLICAÇÃO DA IMUNIDADE TRIBUTÁRIA AOS LIVROS ELETRÔNICOS E E- READERS}

É sabido que a norma jurídica deve acompanhar o momento histórico, social e político da sociedade, mantendo-se atualizada a fim de alcançar sua finalidade precípua.

Nesse sentido estão os ensinamentos de Bonavides:

Quanto mais rígida a Constituição, quanto mais dificultosos os obstáculos erguidos a sua reforma, mais avulta a importância da interpretação, mais flexíveis e maleáveis devem ser os seus métodos interpretativos, em ordem a fazer possível uma perfeita acomodação do estatuto básico às exigências do meio político e social. Do contrário, com a Constituição petrificada, teríamos a rápida acumulação de elementos de crise, que sempre prosperam e rompem, por vias extraconstitucionais, o dique de formalismos e artifícios teóricos levantados nos textos pela técnica das Constituições. (BONAVIDES, 2003, p. 458-459).

Sendo assim, a interpretação constitucional deve ser renovada com o tempo, sob pena de a Constituição Federal tornar-se obsoleta e destoante da realidade social, observando-se, é claro, a finalidade a qual a norma se propõe a fim de não conceder interpretação completamente diversa.

Nesse ínterim, a difusão dos livros eletrônicos rompe paradigmas e põe em questão não só a interpretação do texto constitucional, mas o próprio conceito de livro.

Sobre o tema, ensina Chartier:

As mutações de nosso presente transformam, ao mesmo tempo, os suportes da escrita, a técnica de sua reprodução e disseminação, assim como os modelos de ler. Tal simultaneidade é inédita na história da humanidade.

Ao quebrar o vínculo antigo estabelecido entre textos e objetos, entre discursos e sua materialidade, a revolução digital obriga a uma revisão radical dos gestos e das noções que associamos ao escrito. (CHARTIER, 2010).

De acordo com Silva, "a primeira publicação oficial de um livro eletrônico foi o título 'On Murder Considered as one of the Fine Arts', do autor Thomas de Quincey”' (SILVA, 2014, p.37). Esse produto em formato pode ser lido por qualquer leitor eletrônico, como tablets, smartphone, computador ou os e-readers, que são aparelhos especialmente desenvolvidos para o produto em questão.

Ressalta-se que o conceito de livro sofreu constante processo de evolução ao longo tempo. Segundo Caldeira, "o livro tem aproximadamente seis mil anos de história e o homem utilizou os mais diferentes tipos de materiais para registrar a sua passagem pelo planeta e difundir seus conhecimentos e experiências. (CALDEIRA, 2002). 
Nesse sentido ensina Carrazza:

O papel, apenas, foi, por largo tempo, o suporte material por excelência do livro, no sentido considerado pela Constituição, para fins de imunidade: veículo de transmissão de ideias. Inventado pelos chineses e trazido para a Europa nos fins da Idade Média, o papel, sendo muito mais barato, veio a substituir, com vantagens, o papiro, dos antigos egípcios. Mas, ninguém em sã consciência sustentará - mesmo nos dias que ora correm - que um papiro, contendo ideias, não é livro. (CARRAZZA, 2013, p. 921-922).

Nessa toada, o livro eletrônico é claramente uma nova roupagem da versão em papel, moldada aos tempos atuais. Essa nova formatação traz consigo diversas benesses, como maior funcionalidade, leveza, economia do espaço físico, dentre outros.

Ocorre que esse entendimento está longe da unanimidade. Parte da doutrina ainda encontra no modelo físico - aquele impresso em papel - fundamentos determinantes para o reconhecimento da garantia constitucional. Segundo Torres, "pode-se dizer que livro é o resultado da impressão, em papel, de ideias, doutrinas ou informações com finalidade cultural. Aproxima-se, em acepção ampla, do conceito que o senso comum admite e os dicionários registram”. (TORRES, 2005, p. 307).

Da mesma forma, Baleeiro aduz:

Livros, jornais e periódicos são todos os impressos ou gravados, por quaisquer processos tecnológicos, que transmitam aquelas ideias, informações, comentários, narrações reais ou fictícias sobre todos os interesses humanos, por meio de caracteres alfabéticos ou por imagens e, ainda, por signos Braille destinados a cegos. A Constituição não distingue nem pode o intérprete distinguir os processos tecnológicos de elaboração dos livros, jornais e periódicos, embora os vincule ao papel como elemento material de seu fabrico. Isso exclui, pareceu-nos, outros processos de comunicações do pensamento, como a radiodifusão, a $\mathrm{TV}$, os aparelhos de ampliação de som, a cinematografia, etc., que não têm por veículo o papel. (BALEEIRO apud TORRES, 2005, p. 307-308).

Por mais respeitável que seja o posicionamento dos referidos doutrinadores, não é razoável crer que o texto constitucional vinculou o conceito de livro ao modelo impresso em papel. Certamente, o legislador constituinte originário estabeleceu a imunidade tributária ao papel destinado a impressão dos livros justamente por ser o principal suporte físico do produto naquele momento.

O fato de o constituinte de 1988 não ter abrangido expressamente o livro eletrônico na norma imunizante não significa que o interprete não possa adotar, para a mesma norma, interpretação mais adequada. Segundo Machado (2014), a realidade vivida pelo constituinte já 
se dissipou, pois nos últimos anos a evolução tecnológica tem sido simplesmente impressionante.

Ressalta-se que, apesar de a instituto imunizante em questão ser estabelecido de forma objetiva, ou seja, não importando o conteúdo do livro ou periódico, a tendência da jurisprudência é no sentido de sua ampliação, conforme ensina Kiyoshi Harada:

Apesar de a imunidade do livro ser de natureza objetiva, como reconhece a doutrina, a tendência da jurisprudência é no sentido de sua ampliação, a exemplo do que vem ocorrendo com a imunidade do papel destinado à sua impressão, considerada como abrangente de qualquer material suscetível de ser assimilado ao papel utilizado no processo de impressão. (HARADA, 2016, p. 425).

$\mathrm{Na}$ verdade, deve-se compreender o papel como um dos suportes materiais utilizados para a propagação do conhecimento e não como elemento indispensável ao reconhecimento da desoneração prevista no art. 150, inciso VI, alínea d, da Constituição Federal.

Assim ensina Eduardo Sabbag:

A nosso sentir, os livros são suportes materiais utilizados à propagação de um pensamento formalmente considerado. Nesse passo, o livro deve conter uma base física (em papel ou em mídia eletrônica) e uma finalidade "espiritual" de geração do bem educativo (SABBAG, 2014, p. 372).

Nesse ínterim, Machado afirma que "o importante é prestigiar a liberdade de expressão, independentemente do suporte físico difusor do conhecimento ou da forma de transmissão". (MACHADO, 2014, p. 372). Além do mais, para Carvalho, "de nada vale arguir que a frequência da edição seja pequena, que o livro tenha características especiais, ou, ainda, que o papel não seja o mais indicado para a impressão. Provado o destino que se lhe dê, haverá a imunidade”. (CARVALHO apud SABBAG, 2014, p. 372).

Fechar os olhos ao novo paradigma criado pela evolução tecnológica, nesse caso, traduz demasiado apego aos veículos tradicionais de difusão de conhecimento e assimilação inadequada do meio eletrônico, prejudicando a finalidade precípua da norma imunizante.

Para Machado, essa compreensão leva a norma imunizante a uma forma de esclerose precoce:

Como é inegável que os meios magnéticos, produtos da moderna tecnologia, são hoje de fundamental importância para a realização desse mesmo objetivo, a resposta afirmativa se impõe. O entendimento contrário, por mais respeitáveis que sejam, e são, os seus defensores, leva a norma imunizante a uma forma de esclerose precoce, inteiramente incompatível com a doutrina do 
moderno constitucionalismo, especialmente no que concerne à interpretação especificamente constitucional. (MACHADO, 2014, p. 295).

Ainda segundo o supracitado autor, "não pode, pois, o intérprete deixar de considerar essa evolução. Nem esperar que o legislador modifique o texto. O melhor caminho, sem dúvidas, para que o Direito cumpra o seu papel na sociedade, é a interpretação evolutiva". (MACHADO, 2014, p. 296). Nessa perspectiva, ensina Hiyoshi Harada:

Com o avanço da moderna tecnologia na área da informática, o conceito de livro deixou de considerar o aspecto físico, apegando-se ao objeto cultural, ou seja, o livro passou a ser assim entendido pela sua função básica de transmitir e conservar informações. (...). Não vemos qualquer razão para desprezar a interpretação do texto constitucional à luz de nova realidade, que deixou de considerar o livro como objeto físico, apegando-se a um conceito ultrapassado, vigente à época de sua elaboração. (HARADA, 2016, p. 426).

Constata-se que o autor visa justamente o caráter dinâmico do texto constitucional, adequando-o à nova realidade oriunda dos avanços tecnológicos a fim de manter a finalidade primeira do instituto imunizante, qual seja, a difusão do conhecimento, cultura e liberdade de expressão. Ainda nesse sentido, ressalta Harada:

A legitimidade do direito repousa exatamente no seu caráter dinâmico, muitas vezes, exteriorizado por meio de interpretações à luz da realidade vigente. Por simetria à imunidade do livro em seu sentido atual, a jurisprudência estendeu a imunidade sobre todo material destinado à sua impressão, o que abarca todos os materiais e insumos necessários à confecção do jornal, inclusive o maquinário utilizado para tanto. (HARADA, 2016, p. 426).

A fim de consubstanciar seu posicionamento, o referido autor ressalta o entendimento exarado no XXIII Simpósio de Direito Tributário, realizado em São Paulo:

O XXIII Simpósio de Direito Tributário, realizado em São Paulo, no dia 1710-98, sob coordenação de Ives Gandra da Silva Martins, por expressiva maioria, entendeu que a imunidade do art. 150, VI, d, da CF é extensiva ao denominado livro eletrônico (CD-Roms e disquetes). Assim entendeu, porque essa imunidade outorgada de conformidade com os valores da liberdade, da cultura e da educação não comporta interpretação restrita ao livro tradicional, pois, a nova realidade decorrente da ciência da informática possibilita, igualmente, a transmissão de ideias por vias eletrônicas. (HARADA, 2016, p. 425).

Tal relato de Kiyoshi Harada se mostra relevante, pois observa-se que já naquele ano havia a preocupação acerca do avanço tecnológico relacionado ao livro e seu consequente benefício a partir do instituto imunizante previsto na Constituição Federal. Ademais, demonstra o quanto a tecnologia avançou nesses últimos anos, tendo em vista que, hoje em 2016, não se vislumbra mais como relevante a tecnologia do CD-Rom ou do disquete. Hoje, com o desenvolvimento progressivo da rede mundial de computadores, os livros eletrônicos possuem 
um mercado virtual em desenvolvimento que possui como campo a internet, bem como o aperfeiçoamento de dispositivos desenvolvidos especificamente para a leitura desses $e$-books (livros virtuais).

Nesse diapasão, vale observar a recente evolução dos $e$-readers, aparelhos desenvolvidos especialmente para a leitura dos livros eletrônicos, como o Kindle da empresa Amazon, o Kobo e o Lev, estes dois últimos disponibilizados no Brasil pela Livraria Cultura e pela Livraria Saraiva, respectivamente. Esses aparelhos possuem a tecnologia conhecida como "tinta eletrônica", a qual evita o cansaço dos olhos ao decorrer da leitura, se assemelhando ao livro impresso. Diferente dos tablets e computadores que apenas incorporam a função de leitor digital entre suas infinitas possibilidades, os e-readers, como dito anteriormente, são configurados especialmente para a leitura dos livros eletrônicos, tornando-se veículos por excelência desse novo produto.

Por conta disso, questiona-se: esses aparelhos também não estariam contemplados pela imunidade prevista no art. 150, VI, “d” da Constituição Federal?

Deve-se concluir que sim, mas com certa cautela, pois somente os aparelhos desenvolvidos especificamente para a leitura de livros eletrônicos - os e-readers - se enquadrariam como veículos legítimos de difusão de conhecimento e cultura, se assemelhando ao papel.

\section{4- ENTENDIMENTO DO SUPREMO TRIBUNAL FEDERAL ACERCA DE CASOS RELACIONADOS À EXTENSÃO DA IMUNIDADE TRIBUTÁRIA DOS LIVROS}

O Supremo Tribunal Federal vem, aos poucos, enfrentando os casos relacionados à extensão da imunidade dos livros à outras situações, porém ainda não firmou posicionamento consolidado a respeito. De acordo com Carlos Felício, “a jurisprudência do STF, ao longo do tempo, tem abrangido pela norma imunizante determinados materiais, como a lista telefônica, os manuais técnicos as apostilas e o álbum de figurinhas. (FELÍCIO, 2013). Nesse ínterim, assevera Kiyoshi Harada:

O STF, por sua vez, consolidando o entendimento no sentido da ampla interpretação da imunidade do livro e do papel destinado a sua impressão, editou a Súmula 657, que assim expressa: "A imunidade prevista no art. 150, VI, d, da CF abrange os filmes e papéis fotográficos necessários à publicação de jornais e periódicos. " No RE n. 595676/RJ, Rel. Min. Marco Aurélio, sob o argumento de que "na era da informática, salta aos olhos a repercussão geral do tema controvertido" foi reconhecida a existência de repercussão geral a controvérsia acerca do alcance da imunidade prevista no art. 150, inciso VI, alínea d, da Carta Política na importação de pequenos componentes 
eletrônicos que acompanham o material didático utilizado em curso prático de montagem de computadores (DJe de 19-8-2011). (HARADA, 2016, p. 426).

Observa-se, portanto, que ao longo dos anos o Supremo Tribunal Federal tem mantido uma interpretação ampla em relação à extensão do instituto imunizante em questão, justamente por contemplar a finalidade precípua da mesma, a fim de não engessar a compreensão do texto da Constituição Federal.

Colacionam-se abaixo alguns julgados do STF a respeito:

EMENTA DIREITO CONSTITUCIONAL E TRIBUTÁRIO. ISS. IMUNIDADE PREVISTA NO ART. 150, VI, "D", DA LEI MAIOR. EXTENSÃO ÀS LISTAS TELEFÔNICAS. PRECEDENTES. ALEGAÇÃO DE FATO GERADOR DIVERSO. MATÉRIA INFRACONSTITUCIONAL. SÚMULA 279/STF. REELABORAÇÃO DA MOLDURA FÁTICA DELINEADA NA ORIGEM. ACÓRDÃO RECORRIDO PUBLICADO EM

19.12.2012. O entendimento adotado no acórdão recorrido não diverge da jurisprudência firmada no âmbito deste Supremo Tribunal Federal, no sentido de que a imunidade tributária prevista em prol de livros, jornais, periódicos e o papel destinado a sua impressão, alcança as listas telefônicas. Divergir do entendimento de que o fato gerador da exação é a edição de listas telefônicas demandaria a reelaboração da moldura fática delineada no acórdão de origem, o que torna oblíqua e reflexa eventual ofensa, insuscetível, portanto, de viabilizar o conhecimento do recurso extraordinário. Aplicação da Súmula 279/STF: "Para simples reexame de prova não cabe recurso extraordinário." Agravo regimental conhecido e não provido. (ARE 778643 $1^{\mathrm{a}}$ T., rel Min. Rosa Weber, 10-06-2014).

O referido julgado reforça o entendimento da Suprema Corte acerca da extensão da imunidade do art. 150, inciso VI, alínea d, da Constituição Federal às listas telefônicas. Apesar de causar certo incomodo por parte de alguns juristas, a justificativa para a referida extensão encontra-se no aspecto objetivo da norma e no conceito de periódico. Nesse sentido, ensina Kiyoshi Harada:

\begin{abstract}
A imunidade estabelecida é objetiva. Não interessa o conteúdo do livro ou periódico. Já se acha superada a jurisprudência que exigia que o conteúdo dessas publicações se revestissem de caráter jornalístico, literário, artístico, cultural ou científico. Livro, no dizer dos dicionários, significa "porção de cadernos manuscritos ou impressos e cosidos ordenamente". E periódico significa publicação que aparece em tempos determinados ou intervalos iguais, contendo informações de caráter geral. Por isso, os catálogos telefônicos encontram-se soba a proteção da imunidade conforme inúmeros pronunciamentos da Corte Suprema. (HARADA, 2016, p. 425).
\end{abstract}

Observa-se, portanto, que a extensão da imunidade tributária em questão pelo Supremo Tribunal Federal às listas telefônicas corresponde justamente ao caráter periódico da mesma e 
também por conter informações de interesse geral, reforçando o norte que o STF vem tomando quando do julgamento desses casos.

Colacionam-se ainda dois julgados da Suprema Corte sobre a extensão da imunidade em tela às apostilas e ao álbum de figurinhas, respectivamente:

MUNIDADE - IMPOSTOS - LIVROS, JORNAIS, PERIÓDICOS E PAPEL DESTINADO À IMPRESSÃO - APOSTILAS. O preceito da alínea "d" do inciso VI do artigo 150 da Carta da República alcança as chamadas apostilas, veículo de transmissão de cultura simplificado. (RE 183.403, $2^{\mathrm{a}} \mathrm{T}$., rel. Min. Marco Aurélio, 07-11-2000).

EMENTA Álbum de figurinha. Imunidade tributária. art. 150, VI, "d", da Constituição Federal. Precedentes da Suprema Corte. 1. Os álbuns de figurinhas e os respectivos cromos adesivos estão alcançados pela imunidade tributária prevista no artigo 150 , VI, "d", da Constituição Federal. 2. Recurso extraordinário desprovido. (RE 179893/SP, $1^{\text {a }}$ T., rel. Min. Menezes Direito, 15-04-2008).

Com isso, constata-se que, ao julgar os referidos casos, tem dado interpretação nitidamente teleológica à maioria dos casos, pois busca alcançar a finalidade da norma dentro do contexto social, especialmente quanto à difusão de conhecimento e cultura. Aliás, o STF, no julgamento do RE 183.403, utilizou o argumento da utilidade para abarcar a imunidade às listas telefônicas, o que parece, para alguns doutrinadores, algo duvidoso.

Nesse viés, o plenário da suprema corte iniciou o julgamento do Recurso Extraordinário 330.817, que discute o alcance da imunidade em questão aos componentes eletrônicos que acompanham materiais didáticos impressos. Tal decisão poderá servir de paradigma para todo o judiciário, principalmente porque, ao reconhecer a repercussão geral, suspendeu o julgamento de outros processos semelhantes, inclusive recursos que versam sobre livros eletrônicos e e-readers.

Recentemente, em agosto de 2014, de acordo com o Informativo n. 753 do STF, o relator Ministro Marco Aurélio negou o provimento ao recurso com o fito de reconhecer a imunidade tributária:

Inicialmente, descreveu o impacto das inovações tecnológicas sobre a realidade fática e sobre o direito. Sublinhou que a informática revolucionara os meios de ensino e de difusão da cultura e do pensamento. Observou que o acesso aos conteúdos didáticos e às informações mais variadas, em razão da rede mundial de computadores, ou por meio de CD-ROMs ou similares, teria sido ampliada de forma extraordinária. (...)

(...). Salientou que o ensino e a exposição de ideias por meio digital teriam se tornado parte essencial e construtiva da cultura moderna, o que diferenciaria em 
estrutura, procedimento, velocidade, facilidade e amplitude de acesso relativo ao que existia antes. (...)

(...). Consignou que a difusão de ideias e a profusão da cultura ainda ocorreriam por meios tradicionais, mas não mais apenas por eles. Lembrou que o invento de Gutemberg manteria utilidade e relevância, agora acompanhado e integrado aos meios digitais e aos elementos eletrônicos.

O recurso foi remetido ao gabinete do Ministro Dias Toffoli para vista no dia 05 de setembro de 2014 e aguarda julgamento do Plenário.

Deve-se velar para que o STF julgue a questão com sensibilidade e acolha o novo paradigma criado pelas novas tecnologias a fim de resguardar o sentido precípuo da norma imunizante, que é a difusão de conhecimento e cultura, contribuindo para o desenvolvimento da educação no Brasil.

\section{4- CONSIDERAÇÕES FINAIS}

As imunidades previstas na Constituição Federal limitam o poder de tributar e com isso resguardam determinados princípios e garantias constitucionais.

Sendo assim, a imunidade prevista no artigo 150, inciso VI, alínea "d” da Carta Magna tem uma razão de ser. O dispositivo claramente busca resguardar valores relacionados à liberdade de expressão, de conhecimento, de comunicação, bem como contribuir para o desenvolvimento educacional e cultural do País.

Como o papel constitui apenas a estrutura física do livro, sendo verdadeiro veículo de informação - assim como já foi um dia o papiro -, deve-se interpretar de maneira extensiva o texto constitucional a fim de compreender veículos mais modernos de difusão de conhecimento, como os livros eletrônicos. Entendimento contrário relegaria à Constituição Federal perspectiva voltada ao futuro, defasando seus institutos.

Nesse viés, os aparelhos desenvolvidos especialmente para a leitura dos livros eletrônicos - e-readers - devem ser imunizados pelo dispositivo em tela, já que a norma constitucional almeja não tributar tudo aquilo que serva de suporte ao desenvolvimento do livro, da mesma forma como acontece com o papel destinado à produção dos livros.

Portanto, o reconhecimento da imunidade tributária aos livros eletrônicos e aos aparelhos destinados especialmente à sua leitura permite a atualização do texto constitucional, adequandoa ao novo paradigma decorrente da expressiva evolução tecnologia vivenciada nos últimos anos pela sociedade, permitindo, assim, a consagração dos institutos imunizantes a partir da sua finalidade precípua, qual seja, contribuir para a difusão de conhecimento e cultura, bem como satisfazer o exercício da liberdade de expressão. 


\section{REFERÊNCIAS}

ÁVILA, Humberto. Argumentação Jurídica e a Imunidade do Livro Eletrônico. In: Revista Diálogo Jurídico. Salvador: CAJ - Centro de Atualização Jurídica, Volume I, n. 5, ago. 2001. Disponível em: <http://www.direitopublico.com.br/pdf_5/DIALOGO-JURIDICO-05AGOSTO-2001-HUMBERTO-AVILA.pdf>. Acesso em: 18 dez. 2014.

Sistema Constitucional Tributário. São Paulo: Saraiva, 2012.

BONAVIDES, Paulo. Curso de Direito Constitucional. São Paulo: Editora Malheiros. 2003.

BRASIL. Supremo Tribunal Federal. Informativo n. 753. Disponível em: <http://www.stf.jus.br//arquivo/informativo/documento/informativo753.htm>. Acesso em: 16 jun. 2015.

. Constituição (1988). Constituição da República Federativa do Brasil. Disponível em: <http://www.planalto.gov.br/ccivil_03/constituicao/constituicao.htm>. Acesso em: 18 ago. 2014.

CALDEIRA, Cinderela. História do Livro. Revista Espaço Aberto - USP. Disponível em: <http://www.usp.br/espacoaberto/arquivo/2002/espaco24out/vaipara.php?materia=0varia> Acesso em: 27 abr. 2015.

CARraZZA, Antônio Roque. Curso de Direito Constitucional Tributário. São Paulo: Malheiros, 2013.

CHARTIER, Roger. Escutar os Mortos com os Olhos. Revista Estudos Avançados - USP, 2010. Disponível em: <http://www.revistas.usp.br/eav/article/view/10510> Acesso em: 27 abr. 2015.

COSTA, Machado; FERRAZ, Anna Candida da Cunha. Constituição Federal Interpretada. São Paulo: Manole, 2012.

COSTA, Regina Helena. Imunidades Tributárias. São Paulo: Malheiros, 2001. p. 35.

HARADA, Kiyoshi. Direito Financeiro e Tributário. São Paulo: Editora Atlas, 2016.

FELÍ́CIO, Carlos Eduardo. STF e a imunidade do livro eletrônico por uma mudança necessária. Revista Jus Navigandi, Teresina, ano 18, n. 3488, 18 jan. 2013. Disponível em: <http://jus.com.br/artigos/23488>. Acesso em: 16 jun. 2015.

FERNANDES, Bernardo Gonçalves. Curso de Direito Constitucional. Salvador: Jus Podivm, 2014.

MACHADO, Hugo de Brito. Curso de Direito Tributário. São Paulo: Malheiros, 2014.

MASSON, Nathalia. Manual de Direito Constitucional. Salvador: Jus Podivm, 2014.

PAUlSEN, Leandro. Direito Tributário Constituição e Código Tributário à Luz da Doutrina e da Jurisprudência. Porto Alegre: Livraria do Advogado, 2014.

SABBAG, Eduardo. Manual de Direito Tributário. São Paulo: Saraiva, 2014. 
SERRA, Mônica de Almeida Magalhães. Tratado das Imunidades e Isenções Tributárias. Verbatim, 2011.

SILVA, Allan Rocha Oliveira. A Imunidade Tributária Aplicada a Livros Digitais e Ereaders à Luz da Interpretação Constitucional. Belém: CESUPA. 2014. 